\title{
Growth and Characterization of Mn-doped ZnO thin films
}

\author{
Camila lanhez Pereira dos Santos*, Ariano De Giovanni Rodrigues, Marcio Peron Franco de Godoy \\ Departamento de Física, Universidade Federal de São Carlos - UFSCar, São Carlos, SP, Brazil. \\ *caianhez@gmail.com
}

Keywords: oxides, diluted magnetic semiconductor, thin films.

\section{Abstract}

This work shows an investigation of $\mathrm{Zn}_{1-\mathrm{x}} \mathrm{Mn}_{\mathrm{x}} \mathrm{O}$ thin films at concentrations up to $\mathrm{x}=0.10$ as well two reference samples: $\mathrm{Mn}_{3} \mathrm{O}_{4}$ and $\mathrm{ZnO}$. The samples were grown by Spray Pyrolysis on top of glass substrates using as precursors zinc acetate dihydrate and manganese acetate tetrahydrate in aqueous solution. The samples were characterized by X-ray Diffraction (XRD), Scanning Electron Microscopy (SEM), and Optical Absorption measurements. $\mathrm{Zn}_{1-\mathrm{x}} \mathrm{Mn}_{\mathrm{x}} \mathrm{O}$ and $\mathrm{Mn}_{3} \mathrm{O}_{4}$ were identified as wurtzite and hausmannites phases respectively. No significant change in the optical gap was observed for concentrations up to $7 \% \mathrm{Mn}$. After an annealing at $500^{\circ} \mathrm{C}$ during one hour, there was a phase transition from $\mathrm{Mn}_{3} \mathrm{O}_{4}$ to $\alpha-\mathrm{Mn}_{2} \mathrm{O}_{3}$. Our results show that the bandgap discrepancies between as-grown and annealed samples are due to presence of both $\mathrm{Mn}^{2+}$ and $\mathrm{Mn}^{3+}$ in as-grown sample as compared to only $\mathrm{Mn}^{3+}$ after annealing.

\section{Introduction}

Diluted magnetic semiconductors (DMS) are materials that couple semiconductor and ferromagnetic properties produced with the aim to increase their advantages over conventional semiconductor devices, such as increased data processing speed, high density data storage, low power consumption of energy, among others. The notorious work by Dietl et. al. ${ }^{1}$, which applied the Zener model in DMS, estimated the Curie temperature for several doped semiconductors with $5 \% \mathrm{Mn}$, and showed that the wide bandgap semiconductors $\mathrm{GaN}$ and $\mathrm{ZnO}$ exhibit Curie temperatures above room temperature. This result aroused a strong interest in the $\mathrm{ZnO}$ system doped with transition metals, particularly $\mathrm{Mn}$.

Zinc Oxide $(\mathrm{ZnO})$ is a very interesting material with a wide bandgap $(3.37 \mathrm{eV})$ suitable to transparent optoelectronic devices. Furthermore, Manganese has been the subject of much attention in recent decades because of the technological application involving its oxides, which many physical and chemical properties are being discovered ${ }^{2}$. Manganese oxides have complex structures, and can be crystallized in $\mathrm{MnO}, \mathrm{Mn}_{3} \mathrm{O}_{4}, \mathrm{Mn}_{2} \mathrm{O}_{3}$ and $\mathrm{MnO}_{2}$ due to the existence of three types of oxidative states of manganese $\left(\mathrm{Mn}^{2+}, \mathrm{Mn}^{3+} \text { and } \mathrm{Mn}^{4+}\right)^{3}$. Thus, these various states of oxidation and location of the $\mathrm{Mn}$ ions in the unit cell modify their structural, electrical and magnetic properties. Among them, $\mathrm{Mn}_{3} \mathrm{O}_{4}$ (found in nature as a hausmannite mineral), is one of the most important oxides since it has been widely used as the main source of ferrite materials ${ }^{4}$, electric storage devices ${ }^{5}$, active catalyst for the decomposition of methylene blue ${ }^{6}$, oxidation of methane and carbon monoxide ${ }^{7}$, among others.

Manganese $(\mathrm{Mn})$ incorporation in $\mathrm{ZnO}$ is a current topic due to new magnetic and optical properties. In addition to many methods applied to obtain $\mathrm{Mn}$ doped $\mathrm{ZnO}$, mainly in nanostructures and powder, Spray-pyrolysis technique (SP) is a low-cost and versatile process that enables the production of thin films.

The pyrolysis of precursor is a chemical reaction that occurs due to breaking of molecular binding at moderate temperatures and the pulverization of a precursor solution allows the production of thin films. SP technique has been widely used for material growth because it is a continuous process that requires only ambient pressure conditions. This process is even more economical than other processes (such as sol-gel and gas condensation) that involve multiple steps or must be performed under vacuum, and still produce good quality samples at high scale. In addition, SP offers considerable possibilities for the controlled synthesis of films due to their high physical and chemical flexibility 8,9 .

In this work, we grown Mn-doped $\mathrm{ZnO}$ thin films as well pure $\mathrm{ZnO}$ and $\mathrm{Mn}$-oxide by SP. Samples 
were analyzed through the techniques $\mathrm{X}$-ray Diffraction (XRD), Scanning Electron Microscopy (SEM) and Optical Transmittance and Absorbance. The effect of annealing is also investigated and our results indicate the predominance of $\mathrm{Mn}^{3+}$ as compared to as-grown samples with two valence states $\mathrm{Mn}^{3+}$ and $\mathrm{Mn}^{2+}$.

\section{Methods and Results}

\section{Samples}

Thin films of $\mathrm{Zn}_{1-\mathrm{x}} \mathrm{Mn}_{\mathrm{x}} \mathrm{O}$ were grown by spray pyrolysis (SP) on top of glass substrates with $\mathrm{Mn}$ concentrations $x=0$ (pure $\mathrm{ZnO}$ ), 0.01, 0.03, 0.05, $0.07,0.10$ and 1 . We employed as metal precursors zinc acetate dihydrate $\left(\mathrm{Zn}\left(\mathrm{C}_{2} \mathrm{H}_{3} \mathrm{O}_{2}\right)_{2} \cdot 2 \mathrm{H} 2 \mathrm{O}\right)$ and manganese acetate tetrahydrate $\left(\mathrm{C}_{4} \mathrm{H}_{6} \mathrm{MnO}_{4} 4 \mathrm{H}_{2} \mathrm{O}\right)$ in aqueous solution with a molarity $\mathrm{M}=10^{-2}$. The flux of solution during deposition was $0.5 \mathrm{~mL} / \mathrm{min}$ using compressed air as carrier gas at $0.1 \mathrm{MPa}$.

The growth process was based on spraying cycles starting at $300{ }^{\circ} \mathrm{C}$ while the substrate temperature drops to $220{ }^{\circ} \mathrm{C}$ as reported elsewhere ${ }^{10}$. The produced samples were divided in half in order to investigate the effect of annealing. The thermal treatment was performed at atmosphere at $500^{\circ} \mathrm{C}$ during one hour.

\section{Structural and Optical Characterizations}

X-rays Diffraction measurements (XRD) were performed by a Shimadzu diffractometer XRD-6100 model with Cu-Ka radiation $(\lambda=1.5406 \AA)$ over the range $2 \theta=10-90^{\circ}$. The morphology was analyzed by Scanning electron microscopy (SEM - JEOL microscope model JSM 5800LV) with a $15 \mathrm{kV}$ electron-beam voltage. Optical transmittance and absorbance measurements were carried out using an Agilent Cary 5000 UV-VIS-NIR spectrophotometer in the $200 \mathrm{~nm}$ - $1400 \mathrm{~nm}$ wavelength range.
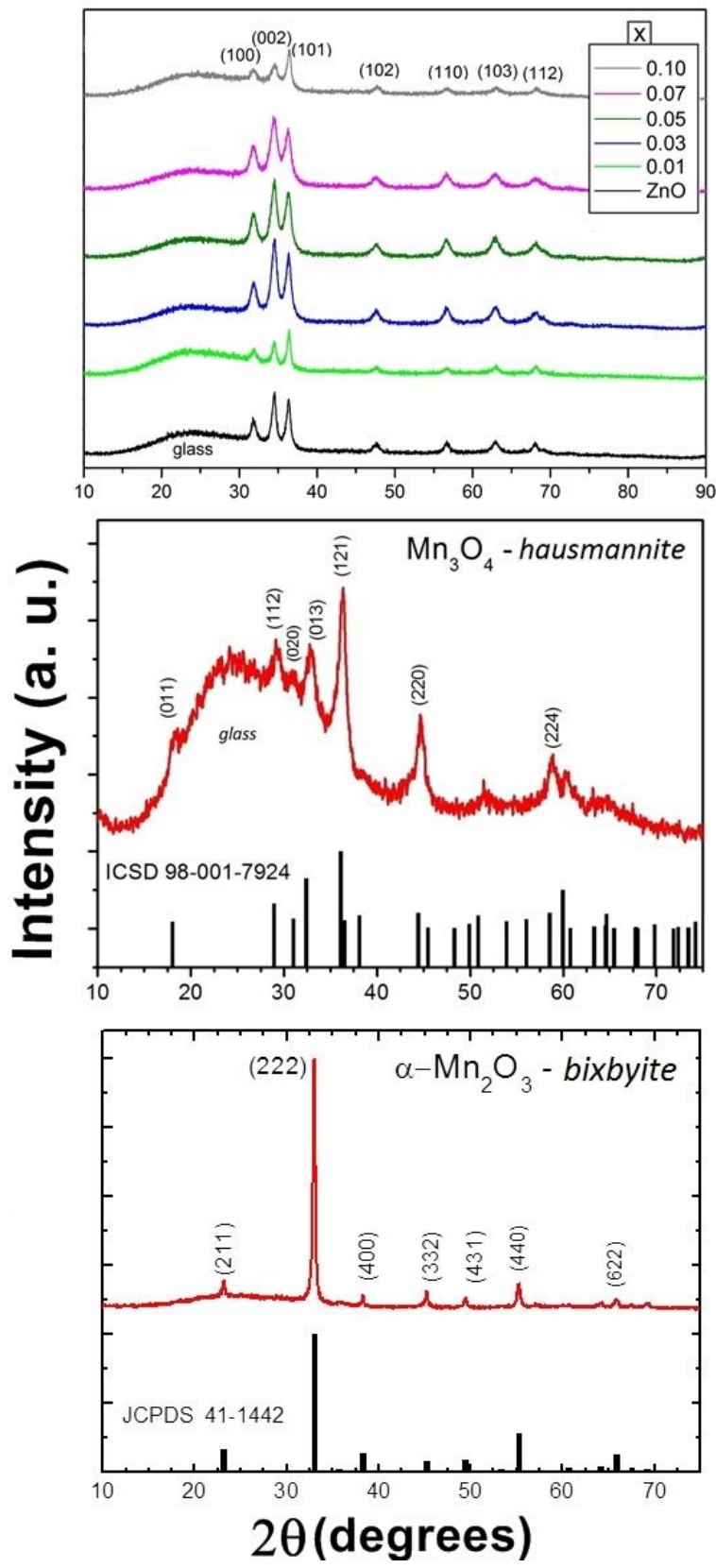

Figure 1: $X R D$ characterization of thin films, from top to bottom: $\mathrm{Zn}_{1-x} \mathrm{Mn}_{\mathrm{x}} \mathrm{O}$, as-grown $\left(\mathrm{Mn}_{3} \mathrm{O}_{4}\right)$ and annealed $\left(\mathrm{Mn}_{2} \mathrm{O}_{3}\right)$ manganese oxides.

Figure 1 shows the XRD measurements for $\mathrm{Zn}_{1}$. ${ }_{x} \mathrm{Mn}_{\mathrm{x}} \mathrm{O}$ and as-grown and annealed manganese oxide. The broad band around $2 \theta=25^{\circ}$ is due to amorphous glass substrate. It can be noted that all $\mathrm{Zn}_{1-\mathrm{x}} \mathrm{Mn}_{\mathrm{x}} \mathrm{O}$ samples presents wurtzite phase, grown preferably on directions (002) and (101). No Mnrelated secondary phases are identified in the limit of detection. 
Crystallite sizes can be evaluated by applying Scherrer equation in the (002) peak. Calculated sizes are $15 \mathrm{~nm}$ for pure $\mathrm{ZnO}$ and decrease to $11 \mathrm{~nm}$ for $x>0.03$. The annealing does not affect strongly the crystallite sizes and no secondary phases appear in the limit of detection as compared to manganese oxides patterns in Figure 1. In contrast, the scenario is quite different for manganese oxides samples.

As-grown manganese oxide presents hausmanitte phase $\left(\mathrm{Mn}_{3} \mathrm{O}_{4}\right)$, strongly oriented to (121) direction, a tetragonal structure which presents both +2 and +3 manganese valence and lattices parameters $a=5.76 \AA$ and $c=9.46 \AA$. Crystallite size in this case is $8 \mathrm{~nm}$. The annealing causes a structural phase change, in which hausmanitte $\mathrm{Mn}_{3} \mathrm{O}_{4}$ becomes $\alpha$ $\mathrm{Mn}_{2} \mathrm{O}_{3}$ in the bixbyite phase, a cubic structure with lattice parameter $a=9.41 \AA$. This phase change can be interpreted due to loss of oxygen, which stabilizes manganese oxide in +3 valence. Crystallite size increases drastically to $25 \mathrm{~nm}$, calculated from (222) peak.

SEM images with magnification of 1000x are shown in the Figure 2. As-grown samples (left) present a homogeneous surface with large round structures as manganese content increases. In contrast, $\mathrm{Mn}_{3} \mathrm{O}_{4}$ presents a uniform surface. However, when subjected to annealing at $500^{\circ} \mathrm{C}$ manganese diffusion starts to occur, causing a formation of flaked structures, as observed in the right side of Figure 2 (labeled as $A$ ). The flaking starts for small $\mathrm{X}=0.01$ content and increases as $\mathrm{X}$ increases. For pure Mn-oxide, the formation of holes and metallic-like droplets is observed for $\mathrm{Mn}_{2} \mathrm{O}_{3}$ film formed from the $\mathrm{Mn}_{3} \mathrm{O}_{4}$ as-grown film.

Figure 3 exhibits the optical transmittance measurements, which show a high transparency in the infrared region. Pure $\mathrm{ZnO}$ presents a high transparency in the visible range also observed at naked eye. As Mn concentration increases, the films lose the transparency in the visible range due to the red shift of optical absorption near band edge, which can be associated to the bandgap $E_{g}$. Despite absorbing the visible light, Manganese-oxides $\mathrm{Mn}_{3} \mathrm{O}_{4}$ and $\mathrm{Mn}_{2} \mathrm{O}_{3}$ still present a large transparency above $1250 \mathrm{~nm}$.
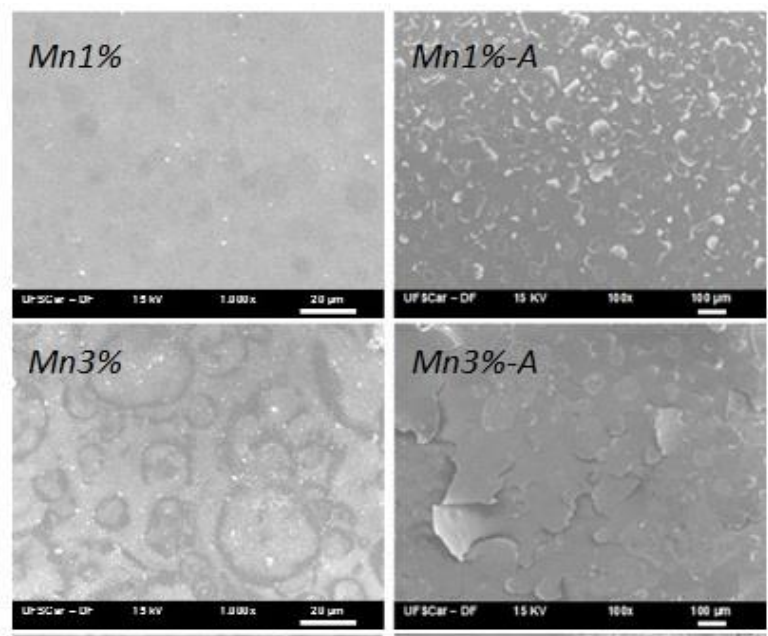

$M n 3 \%-A$
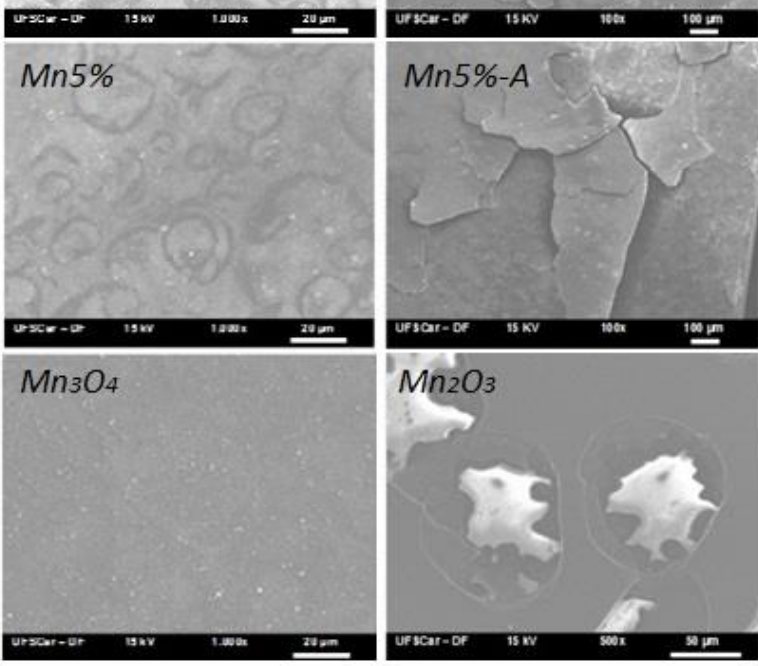

Figure 2: The first column shows the as-grown samples. Second column presents the annealed samples with same set of concentrations $x$.

The absorbance measurements were used to estimate bandgap $E_{g}$ considering a direct bandgap in the Tauc's equation:

$$
(\alpha h v)^{2}=\left(h v-E_{g}\right)
$$

Where $\alpha=$ absorption coefficient $h v=$ photon energy and $E_{g}=$ gap energy.

The results are summarized in the Figure 4. For small content $x=0.01$, the bandgap remains constant at $3.37 \mathrm{eV}$ for as-grown and annealed samples. As $\mathrm{x}$ increases, as-grown samples do not show substantial change in bandgap up to $x=0.07$. In case of $x=0.10, E_{g}$ decreases $52 \mathrm{meV}\left(E_{g}=2.85 \mathrm{eV}\right)$. The as-grown $\mathrm{Mn}_{3} \mathrm{O}_{4}$ presents $\mathrm{E}_{\mathrm{g}} \sim 2.03 \mathrm{eV}$ as reported by other authors employing other growth techniques like hydrothermal route ${ }^{11}$. 


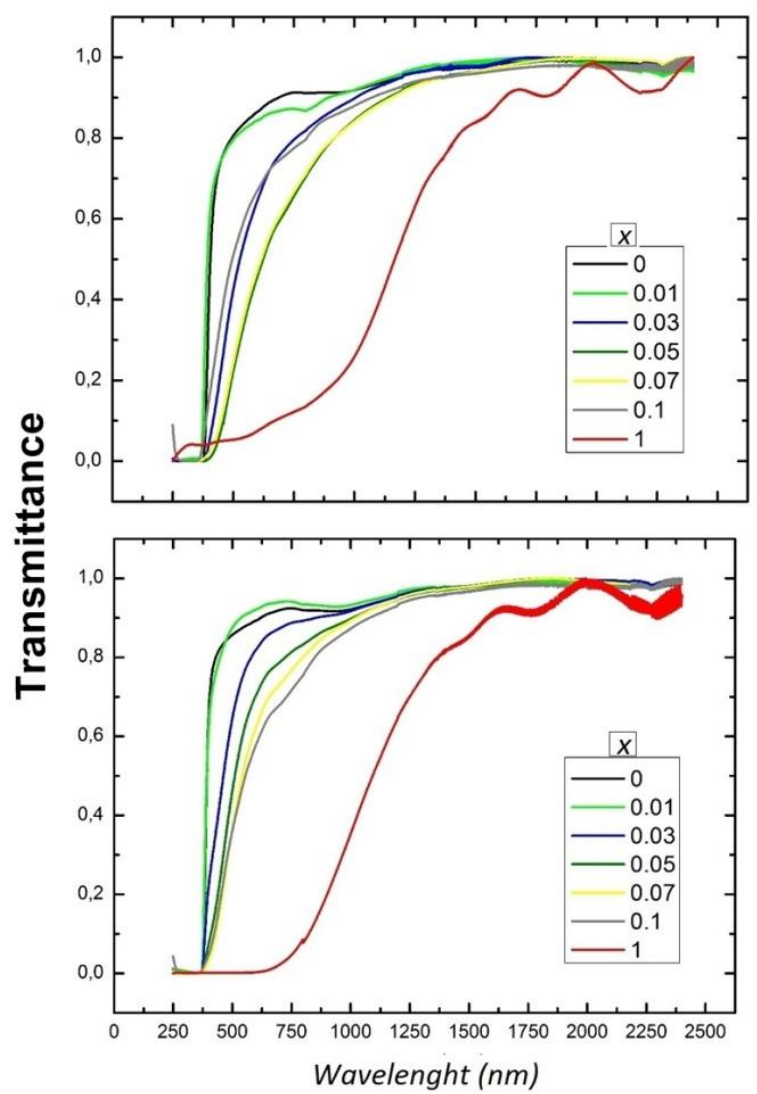

Figure 3: Optical transmittance for annealed samples (top) and as-grown samples (bottom).

The bandgap of annealed samples exhibits a strong redshift starting with $x=0.03$. The bandgap is $1.76 \mathrm{eV}$ for $\mathrm{x}=0.07 . \mathrm{Mn}_{2} \mathrm{O}_{3}$ shows the smaller bandgap $E_{g} \sim 1.33 \mathrm{eV}$ as reported in literature ${ }^{12}$. It is notable that this value is the limit of an ideal absorber in the Shockley-Queisser model.

As observed in the phase transition between the manganese oxides, we can consider that the main effect due to annealing was the change of $\mathrm{Mn}$ valence states between a mixing $2+$ and $3+$ in the as-grown $\mathrm{Mn}_{3} \mathrm{O}_{4}$, which under annealing stabilizes in a unique +3 valence in $\mathrm{Mn}_{2} \mathrm{O}_{3}$. This can be interpreted as a consequence of stoichiometry breaking due to oxygen loss in the structure. Considering the same behavior for $\mathrm{ZnMnO}$, in the as-grown samples the $\mathrm{Mn}$ atoms can present both valences and the 2+ valence can occupy a substitutional site in the $\mathrm{ZnO}$ structure. As a result, small effect on the electronic band structure is observed, mainly in the bandgap. Under annealing, thermal energy allows a segregation of $\mathrm{Mn}$ atoms, summed to an oxygen loss. The main valence for $\mathrm{Mn}$ is now +3 , which tends to occupy interstitial sites in the $\mathrm{ZnO}$ structure. As a consequence, the bandgap now is very sensitive to $\mathrm{Mn}$ concentration and high content $\mathrm{Mn}$ samples forms $\mathrm{Mn}_{2} \mathrm{O}_{3}$ rich regions which are not detect in the limit of $X R D$ precision.

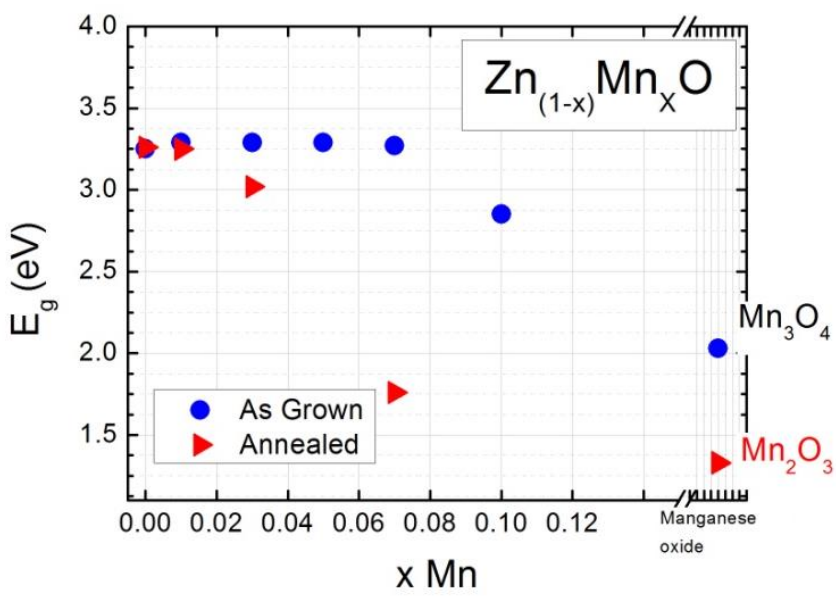

Figure 4: Bandgap for $\mathrm{Zn}_{1-\mathrm{x}} \mathrm{Mn} \mathrm{n}_{\mathrm{X}} \mathrm{O}$ thin films.

\section{Discussion}

Our work shows that Spray-Pyrolysis is an appropriated technique to produce $\mathrm{Mn}$-doped $\mathrm{ZnO}$ and Mn-oxides. XRD measurements corroborates the maintenance of wurtize structure with $\mathrm{Mn}$ concentrations up to $10 \%$. Additionally Mn-oxide stabilizes in the hausmanitte phase $\mathrm{Mn}_{3} \mathrm{O}_{4}$ in asgrown sample. Annealing at $500^{\circ} \mathrm{C}$ causes a phase transition from $\mathrm{Mn}_{3} \mathrm{O}_{4}$ to $\mathrm{Mn}_{2} \mathrm{O}_{3}$.

The bandgap of as-grown $\mathrm{Zn}_{1-\mathrm{x}} \mathrm{Mn}_{\mathrm{x}} \mathrm{O}$ samples is constant up to $x=0.07$ while after annealing, a strong red shift is observed from $x=0.03$. Comparing the results between $\mathrm{Mn}_{3} \mathrm{O}_{4}$ (bivalent $\mathrm{Mn}^{2+}$ and $\mathrm{Mn}^{3+}$ ) and $\mathrm{Mn}_{2} \mathrm{O}_{3}$ (monovalent $\mathrm{Mn}^{3+}$ ), the contribution to the redshift for annealed samples is caused by increase of monovalent $\mathrm{Mn}^{3+}$ as compared to substitutional $\mathrm{Mn}^{2+}$ present in as-grown samples.

\section{Acknowledgments}

The authors thank the support by FAPESP (2016/10973-4), Natalia A. Zanardi for XRD measurements and Diego Scolfaro da Silva for thickness measurements.

1 Dietl, T. et al. Zener model description of ferromagnetism in zincblende magnetic semiconductors. Science, American Association for the Advancement of Science, v. 287, n. 5455, p. 1019-1022, (2000). 
2 Chen, Y.S., C.-C. Hu, Y.-T. Wu, J. Solid State Eletrochem. 8 (2004) 467.

3 Lee, J.D., Concise Inorganic Chemistry, 4th ed., Chapman-Hall, London, 1991, p. 734.

4 Grootendorst, E., Y. Verbeek, V. Ponce, J. Catal. 157 (1995) 706.

5 SARANGAPANI, S., B.V. Tilak, C.P. Chen, J. Electrochem. Soc. 143 (1996) 3791

6 Yang, Z., Y. Zhang, W. Zhang, X. Wang, Y. Qian, X. Wen, S. Yang, J. Solid State Chem. 179 (2006) 679.

7 Stobbe, E.R., B.A.D. De Boer, J.W. Geus, Catal. Today 47 (1999) 161.

8 Messing, G.L., S.C. Zhang, G.V. Jayanthi, J. Am. Ceram. Soc. 76 (1993) 2707.

9 Vergnieres, L., P. Odier, F. Weiss, C.-E. Bruzek, J.-M.Saugrain, J. Eur. Ceram. Soc. 25 (2005) 2951.

10 De Castro, S., dos Reis, S.L., Rodrigues, A.D., de Godoy, M.P.F., Materials Science and Enginnering B 212 (2016) 96.

11 A. Jha, R.Thapa,K.K.Chattopadhyay, Materials Research Bulletin 47 (2012) 813.

12 Ginsburg, A., Keller, D.A., Barad, H.N.; Rietwyk, K., Bouhadana, Y., Anderson, A., Zaban A. Thin Solid Films 615 (2016) 261. 